\title{
Obesity supine death syndrome revisited
}

\section{To the Editors:}

Given the current worldwide epidemic of obesity, it is likely that an increasing number of obese patients will be admitted to hospital in the future [1]. Caring for morbidly obese patients is a critical task that is time-consuming, and requires a trained and motivated staff. One particular hurdle to overcome in the management of these patients is positioning. Unfortunately, this is rarely considered a high priority issue in the emergency setting, despite the potential for dramatic cardiopulmonary complications resulting from the supine positioning of massively obese patients. In extreme cases, it may even result in death. This catastrophic phenomenon has been called the "obesity supine death syndrome". However, only two other cases of this condition have been previously reported [2], and therefore it remains relatively unfamiliar to most physicians. We recently managed a 44-yr-old male with a body mass index of $80 \mathrm{~kg} \cdot \mathrm{m}^{-2}$ who immediately developed severe hypoxaemia, seizures and cardiovascular collapse when placed in the supine position. This case gives us an insight into understanding the underlying mechanisms leading to position-induced cardiorespiratory decompensation in morbidly obese patients.

The patient was admitted to the intensive care unit (Schaffner Hospital, Lens, France) with hypercapnic acute respiratory failure. At that time, he was $175 \mathrm{~cm}$ tall and weighed $245 \mathrm{~kg}$. While breathing $6 \mathrm{~L} \cdot \mathrm{min}^{-1}$ oxygen, arterial blood gases showed a $\mathrm{pH}$ of 7.22, carbon dioxide tension of $95 \mathrm{mmHg}$, oxygen tension of $65 \mathrm{mmHg}$ and a bicarbonate concentration of $36 \mathrm{mmol} \cdot \mathrm{L}^{-1}$. Bilevel positive pressure noninvasive ventilation (NIV) was promptly started and a significant clinical improvement ensued. His mother reported that he could not lie down in bed anymore and always slept sitting up. A few hours after his admission, nursing assistants positioned him in the supine position in order to assist him with bathing. Despite continuous NIV providing a high oxygen supply, his arterial oxygen saturation rapidly

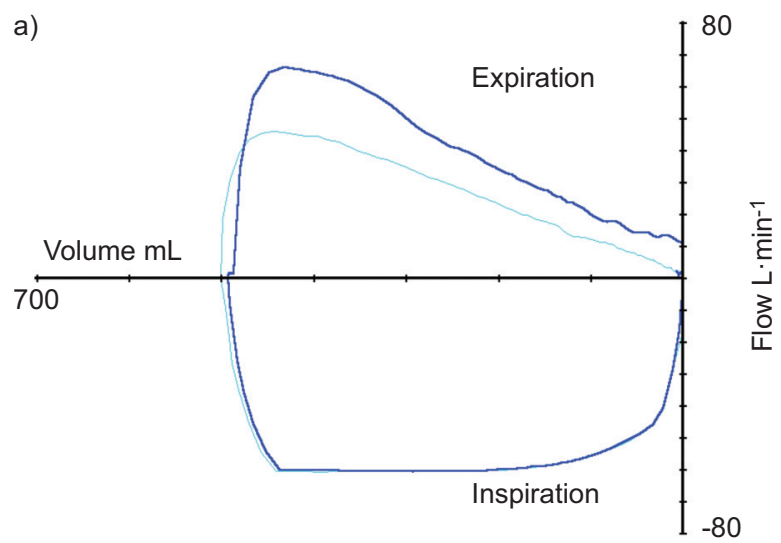

dropped to $60 \%$. His heart rate slowed to 30 beats $\cdot \mathrm{min}^{-1}$, his eyes were rolled back and he began having hypoxic seizures right afterwards. Eight staff members were required to immediately return him to the sitting position. He recovered within a minute without further treatment. We reviewed his cardiovascular and pulmonary history, and found no argument for acute heart failure, pulmonary embolism, pneumothorax, pneumonia or diaphragm paralysis. Nevertheless, we could easily reproduce his sudden hunger for air and feeling of impending death by placing him in the supine position. By recording two consecutive flow-volume curves during NIV and using manual compression of the abdomen during expiration [3], we demonstrated expiratory flow limitation (EFL) when he was lying in the supine position. Conversely, the sitting position totally reversed the EFL resulting in clinical improvement (fig. 1). From then on, all attempts were made to ensure that he was comfortably seated. He was finally discharged 8 days later.

We describe a potentially life-threatening complication of supine position that respiratory physicians need to be aware of when managing morbidly obese patients in acute on chronic respiratory failure. Extremely obese patients in acute respiratory failure should never be allowed to lie completely flat. In these patients, the supine positioning may promote EFL, causing air trapping at the end of expiration, and thereby intrinsic positive end-expiratory pressure (PEEP) $[4,5]$. The underlying mechanism mainly involves the extrinsic compression of the thorax by the huge abdominal compartment, pushing the diaphragm upwards in the supine position. This may result in collapse of the small airways, an increase in the work of breathing [6], severe hypoxaemia $[7,8]$ and depressed cardiac output $[2,9]$.

Another method, the negative expiratory pressure (NEP) technique, has been extensively applied to assess the EFL phenomenon $[4,5,10]$. Using NEP, a transient drop in expiratory flow below the previous control curve shortly after the application of the negative

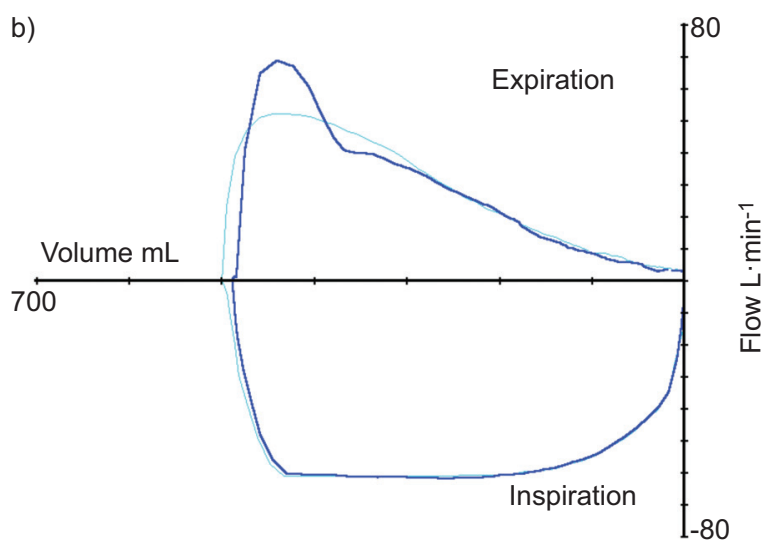

FIGURE 1. Consecutive flow-volume curves during positive pressure noninvasive ventilation. When a gentle manual compression of the abdomen is performed during expiration (dark blue line), the expiratory flow is expected to increase throughout expiration, as compared with the previous control curve (light blue line). This is what happened when our morbidly obese patient was a) seated, whereas b) the supine position induced expiratory flow limitation. 
pressure may reveal upper airway collapsibility. This is especially useful for detecting obstructive sleep apnoea syndrome in obese snorers $[4,10]$. Thus, in the present case, the NEP technique would have allowed the recognition of extrathoracic EFL, which may have contributed to our patient's hypoxaemia. However, when this phenomenon extends to the whole expiration during NEP, it may preclude the detection of intrathoracic EFL with this method [10]. Actually, it is unlikely that upper airway collapse may account for the acute cardiorespiratory disaster experienced by our patient. The patient was awake, he was moved and positive pressure NIV was continuously applied with $8 \mathrm{cmH}_{2} \mathrm{O}$ PEEP during this period. Finally, a growing body of evidence suggests that the deterioration of pulmonary gas exchange that occurs when obese patients are lying down may be the result of ventilation/perfusion mismatch rather than a consequence of hypoventilation $[7,8]$. When morbidly obese patients are lying down, their small airways may extensively collapse in the posterior dependent lung zones. These nonaerated pulmonary areas are well perfused in the supine position and may rapidly lead to severe refractory hypoxaemia [8].

To summarise, it is noteworthy that the sitting position not only ensures comfort but may also be part of a strategy preventing severe cardiorespiratory complications in superobese patients.

\section{Malcolm Lemyze, Mary-Jane Guerry, Jihad Mallat and Didier Thevenin}

Dept of Respiratory and Critical Care Medicine, Schaffner Hospital, Lens, France.

Correspondence: M. Lemyze, Dept of Respiratory and Critical Care Medicine, Schaffner Hospital, 99 route de la Bassée, 62300 Lens, France. E-mail: malcolmlemyze@yahoo.fr
Statement of Interest: None declared.

\section{REFERENCES}

1 Finucane MM, Stevens GA, Cowan MJ, et al. National, regional, and global trends in body-mass index since 1980: systematic analysis of health examination surveys and epidemiological studies with 960 country-years and 9.1 million participants. Lancet 2011; 377: 557-567.

2 Tsueda K, Debrand M, Zeok SS, et al. Obesity supine death syndrome: reports of two morbidly obese patients. Anesth Analg 1979; 58: 345-347.

3 Ninane V, Leduc D, Kafi SA, et al. Detection of expiratory flow limitation by manual compression of the abdominal wall. Am J Respir Crit Care Med 2001; 163: 1326-1330.

4 Ferretti A, Giampiccolo P, Cavalli A, et al. Expiratory flow limitation and orthopnea in massively obese subjects. Chest 2001; 119: 1401-1408.

5 Pankow W, Podszus T, Gutheil T, et al. Expiratory flow limitation and intrinsic positive end-expiratory pressure in obesity. J Appl Physiol 1998; 85: 1236-1243.

6 Steier J, Jolley CJ, Seymour J, et al. Neural respiratory drive in obesity. Thorax 2009; 64: 719-725.

7 Yamane T, Date T, Tokuda M, et al. Hypoxemia in inferior pulmonary veins in supine position is dependent on obesity. Am J Respir Crit Care Med 2008; 178: 295-299.

8 Pelosi P, Croci M, Ravagnan I, et al. Respiratory system mechanics in sedated, paralyzed, morbidly obese patients. J Appl Physiol 1997; 82: 811-818.

9 Pepe PE, Marini JJ. Occult positive end-expiratory pressure in mechanically ventilated patients with airflow obstruction: the auto-PEEP effect. Am Rev Respir Dis 1982; 126: 166-170.

10 Verin E, Tardif C, Portier F, et al. Evidence for expiratory flow limitation of extrathoracic origin in patients with obstructive sleep apnoea. Thorax 2002; 57: 423-428.

DOI: $10.1183 / 09031936.00090812$

\section{High initial multidrug-resistant tuberculosis rate in Buenaventura, Colombia: a public-private initiative}

\section{To the Editors:}

Multidrug-resistant tuberculosis (MDR-TB) is defined as TB resistant to at least isoniazid and rifampicin and globally accounts for approximately 500,000 new cases and 150,000 deaths each year [1]. In the latest nationwide anti-TB drug resistance survey carried out in Colombia (2005), MDR-TB accounted for $2.4 \%$ of new cases (initial MDR-TB) and $31.4 \%$ of previously treated cases [2]. Colombia has 32 departments, $11,000 \mathrm{~TB}$ cases per year and three laboratories to perform drug susceptibility testing (DST). Valle del Cauca is the third most populated department and the one with the highest TB caseloads in Colombia, where previous studies had reported $6 \%$ of initial MDR-TB [3], suggesting that the problem may be greater than in the rest of the country.
A public-private initiative (PPI) led by the Secretariat of Public Health (SPH) of Valle del Cauca and the Centro Internacional de Entrenamiento e Investigaciones Médicas (CIDEIM) was established to assess the anti-TB drug-resistance situation in this department between January 2007 and December 2008, through operational research. The cities were weighted based on elevated rates of TB: Cali and Buenaventura, which represent $70 \%$ of the total caseload in the department $(1,700$ cases per year). This study was approved by the Ethics Committee of CIDEIM.

Included cases were the following: smear-positive pulmonary TB, previously-untreated and/or previously-treated (including relapse, reinfection and treatment failures or defaulters), residing in the city during the last 12 months, regardless of age. Both 